automated program that measures intima media thickness (IMT) by radiofrequency ("Quality intima media thickness in real-time), and the presence of ateroma plaques was evaluated following Mannheim consensus. Pulse wave velocity (PWV) was measured through Mobil o graph ${ }^{\circledR}$ dispositive. We repeat vascular study 3 years later. IMT $\geq 900 \mu$ and $P W V \geq 10 \mathrm{~m} / \mathrm{s}$ were considered as pathological values. Statistical analysis were performed using SPSS 22.0 program.

Results: 108 patients were included. Twelve patients excluded due to high vascular risk [previous event and/or diabetes type II or type I with target organ injury]. Repeated VOP measurement was only available in 49 patients. $64.2 \%$ of patients were women and the mean age was 54.2 (SD 1,3) years. Mean disease duration was 93.1 (SD 12.7) months and mean DAS28 was 1.7 (SD 0.1). 22.4\% of patients received glucocorticoids, $47.8 \%$ NSAIDs, $83.6 \%$ DMARDs and $37.3 \%$ biological drugs. Mean BMI was 26.5 (SD 0.5) $\mathrm{kg} / \mathrm{m}^{2}$. 38.8\%, 28.4\% and $43.3 \%$ of patients were smokers, hypertensive $(11.9 \%$ on ARA2, $3 \%$ on IECA, $1.5 \%$ on calcium channel blockers, $10.4 \%$ on combined treatment) and $43.3 \%$ dyslipidemic [most of them (38.8\%) on statins]. Mean CRP and ESR were 6.2 (SD 0.4) $\mathrm{mg} / \mathrm{l}$ and 9.9 (SD 1) $\mathrm{mm} / \mathrm{h}$, respectively. Mean SCORE was 1.06 (SD 0.1). Baseline, 23.9\% of patients had atheromatous plaques, and $13.4 \%$ and $20.4 \%$ had a pathological IMT or PWV, respectively. Three years later, we detected new and/or atheromatous plaques rises in $19.4 \%$ of patients and PWV and IMT worsening in $10.2 \%$ and $1.5 \%$ of patients, respectively. As per logistic regression analysis, high baseline SCORE (16.9\%), high systolic blood pressure (8.6\%), GF-MDRD (8.2\%), fibrinogen $(6.8 \%)$ and the presence of dyslipidemia were the factors that most contributed to the progression of vascular damage, with independence of the therapeutic objective used for their treatment.

Conclusion: Progression of vascular damage is mainly related to CVRF in patients with PsA, therefore it is essential to intervene on CVRF early. Disclosure of Interests: None declared

DOI: 10.1136/annrheumdis-2019-eular.7329

\section{FRI0455 USE OF SECUKINUMAB IN PSORIATIC ARTHRITIS AND ANKYLOSING SPONDYLITIS...REAL WORLD DATA}

Orlagh Mulholland, Hilary Mckee. Antrim Area Hospital, Rheumatology, Antrim, United Kingdom

Background: Secukinumab was the IL-17 inhibitor licensed for use in Psoriatic Arthritis (PsA) and Ankylosing Spondylitis (AS). The aim of this study was to evaluate the effectiveness and safety of Secukinumab in our cohort of patients.

Objectives: In order to assess the effectiveness and safety of Secukinumab, a retrospective analysis of patients treated with this drug in the Northern Health and Social Care Trust was undertaken.

Methods: Retrospective data was collected from the Local Biologic database. All patients who were on Secukinumab were selected. They were divided into two arms, Psoriatic Arthritis and Ankylosing Spondylitis. From this baseline disease severity was sought, baseline inflammatory markers and patient cohort data was collected. Patients were seen routinely at three monthly intervals and outcomes were collected up to a 12 month period. From patient notes drug response and adverse effects were recorded.

Results: A total of 41 patients with psoriatic arthritis were treated with Secukinumab over the 12-month period studied. Twenty-six patients were female and fifteen were male, with ages ranging from 26 to 70 . Only 12 of the patients were on concomitant methotrexate, all met the NICE start criteria with required DAS 76 scores. Seven of the patients were biologic naïve $(17 \%)$ at commencement of drug.

Of all the patients who responded, most had some response by 3 months, and all had further response by six months.

Sixteen patients $(39 \%)$ discontinued treatment due to no response, one due to increasing shortness of breath, wheeze and rash, and one patient developed colitis.

Other side effects were noted, which did not cause the drug to be discontinued. Five patients had rash and urticaria, three reported headaches. Infections were fairly common, five patients had chest infections, four had sinusitis and three had urinary tract infections. Four patients reported thrush, one oral thrush and three vaginal.

A total of 18 patients with Ankylosing Spondylitis were commenced on Secukinumab. 11 males and 7 females. A third $(6 / 18)$ were biologic naïve. Ages ranged from 27 to 65 .

In the first three months of commencement there was a reduction in BADSAI scores of all patients. This remained at six months. Inflammatory markers CRP and ESR were also reduced.

Seven patients discontinued Secukinumab after six months due to side effects or lack or perceived response by the patient (seen in 1 patient).
Two patients had a loss of efficacy. The remaining four patients noted cutaneous skin infections, sinus symptoms or headaches as noted in the PsA arm of the audit.

Conclusion: Patients in the Northern Trust starting Secukinumab generally have severe disease and most have had prior treatment with biologics.

There was a high incidence of non responders in this group, however in those patients who responded there was a good response rate at 3 months, and these patients were still on treatment at 12 months. Side effects were as expected, with infections being the most commonly reported side effect.

\section{REFERENCES}

[1] Robertson J, Tindell A, Crosbie D, Siebert S. Real-world experience of secukinumab for psoriatic arthritis and axial spondyloarthritis. Rheumatology. Volume 57. Issue suppl_3, April 2018.

Acknowledgement: Department of Rheumatology Antrim Area Hospital Disclosure of Interests: None declared

DOI: 10.1136/annrheumdis-2019-eular.6369

\section{FRI0456 1 THE EFFECT OF GENDER ON DISEASE ACTIVITY, FUNCTIONAL INDEX AND QUALITY OF LIFE IN PATIENTS WITH AXIAL SPA. THE DATA OF TLAR- NETWORK PSA STUDY}

Kemal Nas $^{1}$, Erkan Kilic ${ }^{2}$, Ibrahim Tekeoğlu ${ }^{1}$, Remzi Cevik ${ }^{3}$, Betul Sargin ${ }^{4}$, Sevtap Acer Kasman ${ }^{5}$, Hakan Alkan ${ }^{6}$, Nilay Sahin ${ }^{7}$, Gizem Cengiz ${ }^{8}$, Nihan Cuzdan ${ }^{9}$, Ilknu Albayrak Gezer ${ }^{10}$, Dilek Keskin ${ }^{11}$, Cevriye Mülkoğlu ${ }^{12}$, Hatice Resorlu ${ }^{13}$, Şebnem Ataman ${ }^{14}$, Ajda Bal ${ }^{15}$, Mehmet Tuncay Duruöz ${ }^{5}$, Okan Kucukakkas ${ }^{16}$ Ozan Volkan Yurdakul ${ }^{16}$, Meltem Alkan Melikoglu ${ }^{17}$, Yıldıray Aydın ${ }^{1}$,

Figen Ayhan ${ }^{18}$, Hatice Bodur ${ }^{19}$, Mustafa Calis ${ }^{8}$, Erhan Capkin ${ }^{20}$, Gul Devrimsel ${ }^{21}$ Kevser Gok ${ }^{22}$, Sami Hizmetli ${ }^{23}$, Ayhan Kamanlı ${ }^{1}$, Yasar Keskin ${ }^{16}$, Hilal Kocabas ${ }^{24}$ Oznur Kutluk ${ }^{25}$, Nesrin Sen ${ }^{26}$, Omer Faruk Sendur ${ }^{4}$, Murat Toprak ${ }^{27}$, Sena Tolu ${ }^{16}$, Tiraje Tuncer ${ }^{25} .{ }^{1}$ Sakarya Unv, Sakarya, Turkey; ${ }^{2}$ Afyon Hospt, Afyon, Turkey; ${ }^{3}$ Dicle Unv, Diyarbakır, Turkey; ${ }^{4}$ Adnan Menderes Unv, Aydın, Turkey; ${ }^{5}$ Marmara Unv, Istanbul, Turkey; ${ }^{6}$ Pamukkale Unv, Denizli, Turkey, ${ }^{7}$ Balıkesir Unv, Balıkesir, Turkey, ${ }^{8}$ Erciyes Unv, Kayseri, Turkey; ${ }^{9}$ Şanlıurfa Hospt, Şanlıurfa, Turkey;

${ }^{10}$ Selçuk Unv, Konya, Turkey, ${ }^{11}$ Kırıkkale Unv, Kırıkkale, Turkey, ${ }^{12}$ Ankara Traiand Res Hospt, Ankara, Turkey, ${ }^{13}$ Çanakkale 18 Mart Unv, Çanakkale, Turkey;

${ }^{14}$ Ankara Unv, Ankara, Turkey, ${ }^{15}$ Dısskapı Traiand Res Hospt, Ankara, Turkey,

${ }^{16}$ Bezmiâlem Unv, İstanbul, Turkey; ${ }^{17}$ Atatürk Unv, Erzurum, Turkey; ${ }^{18}$ Ankara TraiandRes Hospt, Ankara, Turkey; ${ }^{19}$ Yıldırım Beyazıt Unv, Ankara, Turkey, ${ }^{20}$ Karadeniz Tech Unv, Trabzon, Turkey; ${ }^{21}$ Recep Tayyip Erdoğan Unv, Rize, Turkey, ${ }^{22}$ Numune TraiandRes Hospt, Ankara, Turkey; ${ }^{23}$ Cumhuriyet Unv, Sivas, Turkey, ${ }^{24}$ Necmettin Erbakan Unv, Konya, Turkey; ${ }^{25}$ Akdeniz Unv, Antalya, Turkey, ${ }^{26}$ Kartal Dr. Lütfi Kırdar TraiandRes Hospt, İstanbul, Turkey, ${ }^{27}$ Yuzuncu Yıl Unv, Van, Turkey

Background: PsA is a chronic musculoskeletal disease. The prevalence of axial involvement in PSA varies according to the duration of the disease. In early stage the incidence varies between $5 \%$ and $28 \%$, but it increases up to $25-70 \%$ in later stages of the disease. In the literature, there is limited data on the differences in disease activity, functional status and quality of life of men and women with axial PsA.

Objectives: In this study, we aimed to evaluate the effect of gender dif ference on clinical findings, disease activity, functional status and quality of life in patients with axial involvement in Turkey.

Methods: Patients with PsA who met the CASPAR classification criteria were enrolled consequently in this cohort. Turkish League Against Rheu matism (TLAR)- Network was formed with the participation of 25 centers. The demographic variables, fatigue, diagnostic delay, the beginning of peripheral arthritis, enthesitis, dactylitis and spine involvement, inflammatory lumbar pain, patients' quality of life, BASFI, HAQ, HAQ-s,VAS pain, anxiety, depression and disease activity parameters (TJC, SJC, ESH, DAS28, BASDAI), were recorded. Student's $t$ test and Chi-square test were used to compare variables in SPSS v.22 program.

Results: A total of 1130 patients (36.0\% male, $64.0 \%$ female) with PsA included in this study. In this cohort, 169 male $(46 \pm 12.29)$ and 251 female $(47.4 \pm 12.11)$ had axial involvement. VAS pain $(p<0.001)$, fatigue ( $<0.001)$, ESR $(p<0.001)$, DAS28 ( $<0.001)$, BASDAl score ( $<0.001$ ), PsAQoL ( $p<0.001)$, HAQ score ( $p<0.001)$, HAQ-S score ( $<0.001)$, anxiety ( $p<0.001)$, depression $(p<0.020)$, FACIT $(p<0.001)$ and FIRST $(p<0.001)$ scores were statistically significantly worse in women than males with axial PsA (Table 1). However, SF-36 physical component score ( $p<0.001)$, SF-36 mental component score $(p<0.001)$ and PASI score $(p<0.005)$ were statistically worse in male patients than in female patients with axial involvement. 
Conclusion: This study shown that the burden of disease in axial PsA has a significantly different between genders. Female patients with PsA who have axial involvement have higher disease activity, physical disability, functional limitation and higher depression and anxiety risk than male patients. Therefore, we suggest that new strategies should be developed for more effective treatment of axial PsA in female patients.

Disclosure of Interests: Kemal Nas: None declared, Erkan Kilic: None declared, ibrahim tekeoğlu: None declared, Remzi Cevik: None declared, Betul Sargin: None declared, Sevtap Acer Kasman: None declared, Hakan Alkan: None declared, Nilay Sahin: None declared, Gizem Cengiz: None declared, Nihan Cuzdan: None declared, Ilknur Albayrak Gezer: None declared, Dilek Keskin: None declared, Cevriye Mülkoğlu: None declared, Hatice Resorlu: None declared, Şebnem Ataman: None declared, Ajda Bal: None declared, Mehmet Tuncay Duruöz Grant/ research support from: Abvie, Speakers bureau: Novartis, AMGEN, Abdi İbrahim, Illko, Okan Kucukakkas: None declared, Ozan Volkan Yurdakul: None declared, Meltem Alkan Melikoglu: None declared, Yıldıray Aydın: None declared, Figen Ayhan: None declared, Hatice Bodur: None declared, Mustafa Calis: None declared, Erhan Capkin: None declared, Gul Devrimsel: None declared, Kevser Gok: None declared, SAMI HIZMETLI: None declared, Ayhan Kamanlı: None declared, Yasar Keskin: None declared, Hilal Kocabas: None declared, Oznur Kutluk: None declared, Nesrin Şen: None declared, Omer Faruk Sendur: None declared, Murat Toprak: None declared, Sena Tolu: None declared, Tiraje Tuncer: None declared

DOI: 10.1136/annrheumdis-2019-eular.8305

\section{\begin{tabular}{|l|l} 
FRI0457 SECUKINUMAB PROVIDES SIGNIFICANT AND \\
\hline
\end{tabular} SUSTAINED IMPROVEMENT IN NAIL PSORIASIS AND SIGNS AND SYMPTOMS OF PSORIATIC ARTHRITIS IN PATIENTS WITH NAIL PHENOTYPE: 52-WEEK RESULTS FROM THE PHASE III FUTURE 5 STUDY}

Peter Nash $^{1}$, Philip J. Mease ${ }^{2}$, Bruce Kirkham ${ }^{3}$, Alejandro Balsa ${ }^{4}$, Atul Singhal ${ }^{5}$, Erhard Quebe-Fehling ${ }^{6}$, Luminita Pricop ${ }^{7}$, Corine Gaillez ${ }^{6} .{ }^{1}$ University of Queensland, Brisbane, Australia; ${ }^{2}$ Swedish Medical Center and University of Washington, Seattle, United States of America; ${ }^{3}$ Guy's and St Thomas' NHS Foundation Trust, London, United Kingdom; ${ }^{4}$ Hospital La Paz - IdiPAZ, Madrid, Spain; ${ }^{5}$ Southwest Rheumatology, Dallas, United States of America; ${ }^{6}$ Novartis Pharma AG, Basel, Switzerland; ${ }^{7}$ Novartis Pharmaceuticals Corporation, East Hanover, United States of America

Background: Nail psoriasis ( $\mathrm{PsO}$ ) is present in up to $80 \%$ in psoriatic arthritis (PsA) patients (pts) and associated with significant pain, psychosocial disability, decreased physical function and quality of life (QoL). ${ }^{1}$ Nail PsO is considered as one of the six core PsA domains by GRAPPA $^{2}$ and is a predictor of severe disease with joint involvement and structural damage. Secukinumab (SEC) has demonstrated efficacy for pts with nail PsO in the TRANSFIGURE study ${ }^{3}$ and significant improvement in signs and symptoms of PsA in the FUTURE 5 study $^{4}$

Objectives: To evaluate the efficacy of SEC on nail PSO and other facets of disease in the nail subset from the FUTURE 5 study through 52 weeks (wks).

Methods: Pts ( $\mathrm{N}=996)$ with active PsA, were randomised to subcutaneous SEC $300 \mathrm{mg}$ loading dosage (LD; $300 \mathrm{mg}$ ), $150 \mathrm{mg}$ LD (150 mg), 150 $\mathrm{mg}$ no LD or placebo (PBO). All groups received SEC or PBO at baseline (BL), Wks 1, 2, 3, and 4, and then every 4 wks. Efficacy assessments through Wk 52 included mNAPSI, ACR, PASI, HAQ-DI, SF-36 PCS, PsAQoL and resolution of dactylitis and enthesitis. Analyses through Wk 16 used non-responder imputation (NRI) for binary and mixed-effect model repeated measure (MMRM) for continuous variables. Observed data are presented from Wk 20-52.

Results: A total of 663/996 (66.6\%) PsA pts had concomitant nail PsO at $\mathrm{BL}$. Demographics and $\mathrm{BL}$ disease characteristics were balanced between treatment groups in the nail subset, which were comparable with overall population. The total mean mNAPSI score at BL was 16.4. SEC 300 and $150 \mathrm{mg}$ doses improved nail PsO vs. placebo (PBO) at Wk 8, 12 and $16(P<0.0001)$, with further improvements through Wk 52 (Figure). ACR20/50 and PASI 90 responses, resolution of dactylitis and enthesitis, physical function and QoL were also improved with SEC vs. PBO at Wk 16 with sustained improvements through 52 wks (Table). Conclusion: Secukinumab provided sustained improvements in nail disease, signs and symptoms of PsA, physical function and QoL through 52 wks in pts with PsA and moderate to severe nail PsO.

\section{REFERENCES:}

[1] Baran R. Dermatology 2010;221(Suppl1):1-5.

[2] Coates LC, et al. Arthritis Rheumatol. 2016;68:1060-71.
[3] Reich K, et al. Br J Dermatol. 2018. Doi: 10.1111/bjd.17351.

[4] Mease PJ, et al. Ann Rheum Dis. 2018;77:890-7.

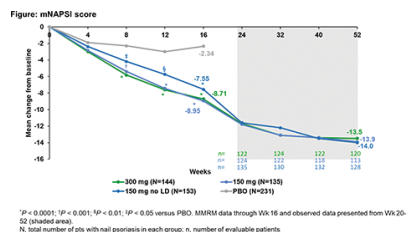

\begin{tabular}{|c|c|c|c|c|c|}
\hline \multirow[b]{2}{*}{ Variable } & \multirow[b]{2}{*}{ Wk } & \multicolumn{3}{|c|}{ SEC } & \multirow{2}{*}{$\begin{array}{c}\mathrm{PBO} \\
\mathrm{N}=\mathbf{2 3 1}\end{array}$} \\
\hline & & $\begin{array}{l}300 \mathrm{mg} \\
\mathrm{N}=144\end{array}$ & $\begin{array}{l}150 \mathrm{mg} \\
\mathrm{N}=135\end{array}$ & $150 \underset{\mathrm{N}=153}{15 \mathrm{mo}} \mathrm{LD}$ & \\
\hline \multirow{2}{*}{$\mathrm{ACR} 20^{1}$} & 16 & $66.7^{\star}$ & $60.0^{*}$ & $61.4^{\star}$ & 29.0 \\
\hline & 52 & $81.2(133)$ & $73.7(118)$ & $77.9(136)$ & - \\
\hline \multirow{2}{*}{ 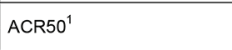 } & 16 & $43.1^{*}$ & $40.7^{*}$ & $32.0^{\star}$ & 9.1 \\
\hline & 52 & $54.1(133)$ & $45.8(118)$ & $50.7(136)$ & - \\
\hline \multirow{2}{*}{ PASI $90^{1,2}$} & 16 & $52.0^{*}$ & $36.8^{\star}$ & $31.0^{*}$ & 7.6 \\
\hline & 52 & $62.3(69)$ & $50.7(75)$ & $49.3(75)$ & - \\
\hline \multirow{2}{*}{$H A Q-D I^{3}$} & 16 & $-0.6^{*}$ & $-0.5^{\star}$ & $-0.5^{*}$ & -0.2 \\
\hline & 52 & $-0.6(132)$ & $-0.6(117)$ & $-0.6(136)$ & - \\
\hline \multirow{2}{*}{ SF-36 PCS ${ }^{3}$} & 16 & $7.82^{\star}$ & $6.90^{*}$ & $6.00^{*}$ & 2.29 \\
\hline & 52 & $8.0(134)$ & $6.71(123)$ & $7.93(137)$ & - \\
\hline \multirow{2}{*}{$\mathrm{PsAQoL}^{3}$} & 16 & $-3.6^{*}$ & $-3.6^{\star}$ & $-3.0^{\dagger}$ & -1.1 \\
\hline & 52 & $-3.9(134)$ & $-4.2(122)$ & $-3.8(137)$ & - \\
\hline \multirow{2}{*}{ Resolution of enthesitis, $\%^{4}$} & 16 & $58.2^{\dagger}$ & $56.8^{\dagger}$ & $47.2^{\ddagger}$ & 34.3 \\
\hline & 52 & $81.5(92)$ & $68.7(80)$ & $70.7(82)$ & - \\
\hline \multirow{2}{*}{ Resolution of dactylitis, $\%^{4}$} & 16 & $63.8^{\dagger}$ & $52.6^{\ddagger}$ & $59.2^{\dagger}$ & 32.4 \\
\hline & 52 & $78.8(52)$ & $79.6(49)$ & $80.3(66)$ & - \\
\hline
\end{tabular}

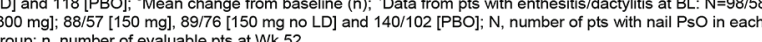

Table. Summary of results

\begin{tabular}{|c|c|c|c|c|c|}
\hline & & & SEC & & PBO \\
\hline Variable & Wk & $\begin{array}{c}300 \mathrm{mg} \\
\mathrm{N}=144\end{array}$ & $\begin{array}{l}150 \mathrm{mg} \\
\mathrm{N}=135\end{array}$ & $\begin{array}{c}150 \mathrm{mg} \text { no } \\
\text { LD } \\
\mathrm{N}=153\end{array}$ & \\
\hline $\mathrm{ACR}_{20}{ }^{1}$ & $\begin{array}{c}16 \\
52\end{array}$ & $\begin{array}{c}66.7^{\star} \\
81.2 \\
(133)\end{array}$ & $\begin{array}{c}60.0^{*} \\
73.7 \\
(118)\end{array}$ & $\begin{array}{c}61.4^{*} \\
77.9(136)\end{array}$ & $\begin{array}{c}29.0 \\
-\end{array}$ \\
\hline $\mathrm{ACR} 0^{1}$ & $\begin{array}{c}16 \\
52\end{array}$ & $\begin{array}{l}43.1^{*} \\
54.1 \\
(133)\end{array}$ & $\begin{array}{c}40.7^{\star} \\
45.8 \\
(118)\end{array}$ & $\begin{array}{c}32.0^{*} \\
50.7(136)\end{array}$ & $\begin{array}{c}9.1 \\
-\end{array}$ \\
\hline PASI $90^{1,2}$ & $\begin{array}{c}16 \\
52\end{array}$ & $\begin{array}{c}52.0^{*} \\
62.3(69)\end{array}$ & $\begin{array}{c}36.8^{*} \\
50.7(75)\end{array}$ & $\begin{array}{c}31.0^{*} \\
49.3(75)\end{array}$ & $\begin{array}{c}7.6 \\
-\end{array}$ \\
\hline $\mathrm{HAQ}-\left.\mathrm{DI}\right|^{3}$ & $\begin{array}{c}16 \\
52\end{array}$ & $\begin{array}{c}-0.6^{*} \\
-0.6(132)\end{array}$ & $\begin{array}{c}-0.5^{*} \\
-0.6(117)\end{array}$ & $\begin{array}{c}-0.5^{*} \\
-0.6(136)\end{array}$ & $\begin{array}{c}-0.2 \\
-\end{array}$ \\
\hline SF-36 PCS $^{3}$ & $\begin{array}{c}16 \\
52\end{array}$ & $\begin{array}{c}7.82^{*} \\
8.0(134)\end{array}$ & $\begin{array}{c}6.90^{*} \\
6.71 \\
(123)\end{array}$ & $\begin{array}{c}6.00^{*} \\
7.93(137)\end{array}$ & $\begin{array}{c}2.29 \\
-\end{array}$ \\
\hline $\mathrm{PsAQoL}^{3}$ & $\begin{array}{c}16 \\
52\end{array}$ & $\begin{array}{c}-3.6^{*} \\
-3.9(134)\end{array}$ & $\begin{array}{c}-3.6^{*} \\
-4.2(122)\end{array}$ & $\begin{array}{c}-3.0^{\dagger} \\
-3.8(137)\end{array}$ & $\begin{array}{c}-1.1 \\
-\end{array}$ \\
\hline Resolution of enthesitis, $\%{ }^{4}$ & $\begin{array}{c}16 \\
52\end{array}$ & $\begin{array}{c}58.2^{\dagger} \\
81.5(92)\end{array}$ & $\begin{array}{c}56.8^{\dagger} \\
68.7(80)\end{array}$ & $\begin{array}{c}47.2^{+} \\
70.7(82)\end{array}$ & 34.3 \\
\hline Resolution of dactylitis, $\%{ }^{4}$ & $\begin{array}{c}16 \\
52\end{array}$ & $\begin{array}{c}63.8^{\dagger} \\
78.8(52)\end{array}$ & $\begin{array}{c}52.6^{+} \\
79.6(49)\end{array}$ & $\begin{array}{c}59.2^{\dagger} \\
80.3(66)\end{array}$ & $\begin{array}{c}32.4 \\
-\end{array}$ \\
\hline
\end{tabular}

${ }^{*} P<0.0001 ;{ }^{\dagger} P<0.001 ;{ }^{\$} P<0.01 ;{ }^{\ddagger} P<0.05$ vs. PBO. NRI data for binary and MMRM data for continuous variables presented at Wk 16. Observed data presented at Wk 52

$1 \%$ responders $(n) ;{ }^{2}$ Data from pts with $B L$ psoriasis $\geq 3 \%$ BSA: $N=75$ [300 mg]; 87 [150 mg], 84 [150 mg no LD] and 118 [PBO]; ${ }^{3}$ Mean change from baseline (n); ${ }^{4}$ Data from pts with enthesitis/dactylitis at BL: $\mathrm{N}=98 / 58$ [300 mg]; 88/57 [150 mg] 89/76 [150 mg no LD] and 140/102 [PBO]; N, number of pts with nail PsO in each group; n, number of evaluable pts at Wk 52

Disclosure of Interests: Peter Nash Grant/research support from: AbbVie Bristol-Myers Squibb, Eli Lilly, Janssen, Novartis, Pfizer Inc, Roche Sanofi, UCB, Consultant for: AbbVie, Bristol-Myers Squibb, Eli Lilly, Jans sen, Novartis, Pfizer Inc, Roche, Sanofi, UCB, Speakers bureau: AbbVie, Bristol-Myers Squibb, Eli Lilly, Janssen, Novartis, Pfizer Inc, Roche, Sanofi, UCB, Philip J Mease Grant/research support from: AbbVie, Amgen, BMS, Celgene, Janssen, Lilly, Novartis, Pfizer, SUN and UCB, Consultant for: AbbVie, Amgen, BMS, Galapagos, Gilead Sciences, Inc. Janssen, Lilly, Novartis, Pfizer, SUN and UCB, Speakers bureau: AbbVie, 